\title{
OPERATION FOR PERSISTENT PUPILLARY MEMBRANE. NOTES ON A CASE* +
}

BY

\section{ZOLTÁN BÁTHORI}

BUDAPEST

SINCE the use of the slit-lamp the diagnosis of persistent pupillary membrane has become very frequent, and even the smallest vestige of the condition can easily be recognised. It may appear in a variety of forms and though the condition is frequent (according to Staehli 31 per cent. of all cases) it is extremely rarely that it interferes with the patient's vision, or that an operation has to be done to improve sight.

The first operated cases were published by Wiegmann (1916). He operated on four eyes of a pair of twins, and after several repeated operations the vision improved. Mawas and Terrien (1922) refer to a histological examination of a persistent pupillary membrane which was removed by operation and in this case too vision had improved. In a case of Noji (1930) optical iridectomy was performed as the persistent pupillary membrane was adherent to the lens capsule and partial lenticular opacities were present. A good result was achieved. Nakame (1937) refers to several operated cases. It is interesting that in spite of the number of reported cases text-books of ophthalmology, or of operative eye surgery do not describe an operation for the condition.

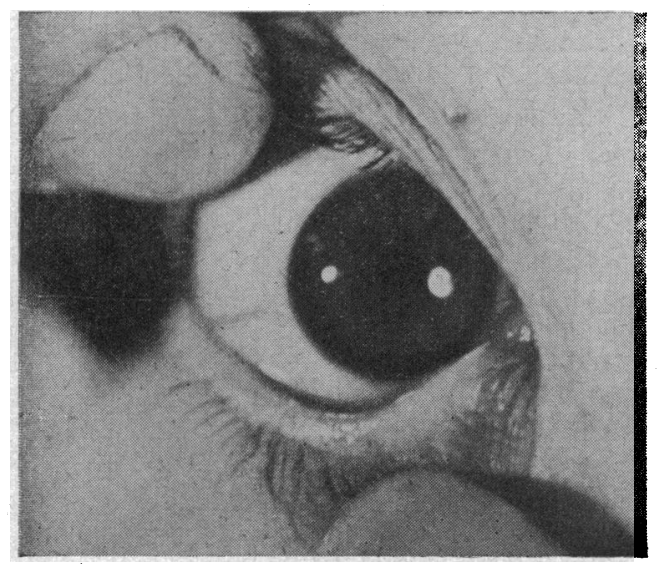

FIG. 1.

* From The Eye Clinic of Pázmány Péter University, Budapest, (Director : Prof. Joseph Imre.)

† Received for publication, January 27, 1948. 
In 1934 I presented a patient to the Hungarian Ophthalmological Society with a dense persistent pupillary membrane occupying the whole area of the pupil (Fig. 1.).

30 years old woman, had always poor vision. She noticed recently further deterioration. V.A. R.E. Counting Fingers $3 \mathrm{~m} .-3.0$ D.sph. 5/50.

L.E. $5 / 30-3.5$ D.sph. 5/12.

Nystagmus of small amplitude, mainly in the horizontal direction.

R.E. The pupillary area was occupied by a mass of brownish tissue, identical in colour with the iris, slightly prominent. With the slit-lamp it showed a derise central part of $1.5 \mathrm{~mm}$. diameter, and from here a mesh of threads of different thickness originated, passing in radial direction towards the iris crypts. The pupillary margin could be seen through the mesh, and the pupil was active. The lens appeared clear.

L.E. showed a similar but less marked picture. The central dense mass was of only $0.5 \mathrm{~mm}$. diameter. Lens, media and fundus showed no abnormal changes.

Operation on the right eye was performed by Professor Imre.

After a keratome incision the filaments were pulled into the wound, one by one, with a small iris hook and severed with de Wecker's scissors, and eventually the whole persistent pupillary membrane was removed. After operation the whole area of the pupil was clear

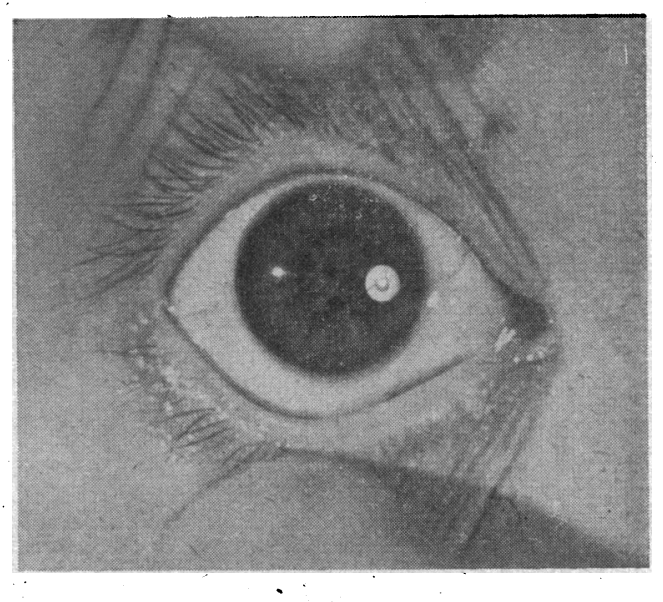

FIG. 2.

(Fig. 2.) and vision had improved with glasses to $5 / 8$ : The left eye was not operated upon.

We think that in cases where the vision is reduced by persistent pupillary membrane an operation is indicated, and the operation of choice is :

(1) as above described, if the persistent pupillary membrane is free and not adherent to the lens capsule, or

(2) an optical iridectomy if it is adherent to the lens capsule. 


\section{REFERENCES}

Staehli.-Ueber Persistent von Resten der fetalen pupillar Membran. Klin. Monatsbl. f. Augenheilk., Vol. LI, p. 1, 1913.

WiegmanN, E.-Zur Operation der persistenden pupillar Membran. Klin. Monatsbl.f. A ugenheilk., Vol. LVII, 1916.

Mawas, I.-Terrien : Etude histologique d'un cas de membrane pupill. persistente, C.r. Biology, Vol. LXXXVII, 1922.

NoJI, R.-Ungewöhliche persistierende pupillar Membran. Klin. Monatsbl. f. A ugenheilk., Vol. LXXXIV, 1930.

Náame, T.-Ueber einige. Fälle von Membrana Pupillaris persistens. GhuoGuako-Iho 29. Referat : Ztbl., 1937.

\section{ANNOTATION \\ Dislocated Lenses}

The lens may be dislocated either forwards or backwards by direct or indirect violence. We remember a case in the latter category in a patient of many years standing. On his first visit he was wearing a medium myopic correction with the stronger glass in the right side. He had a cataract in this eye, the other lens being clear and vision corrected to $6 / 6$ and J.1. The right eye had perception and projection of light and as far as we could see there were no keratic precipitates. This patient visited us for about twenty years at regular intervals. On no occasion could we see any precipitates, but we could never feel quite sure that the condition had not arisen in consequence of some low grade inflammation: and as he was used to his restricted field of vision and had good vision in the other eye we refused to suggest an operation.

This patient about eighteen months before his death had a slight accident. He slipped on his own doorstep and sat down rather heavily. Soon after, he called to say that he could see more light than usual in his bad eye. The upper margin of his lens was visible in the upper part of his pupil and by degrees the lens vanished into the bottom of his eye and vision of $6 / 18$ could be obtained with a suitable lens; but he was not happy and preferred to wear a black patch on the right side. When he died, in his 80th year, the lens was still in the depths of his eye.

On only one occasion were we called upon to deal with a lens dislocated into the anterior chamber. This was in an old man who had been an out-patient for many years. He was a marked case of interstitial keratitis and his left cornea was so much scarred and flattened that the eye was useless. The right eye had very poor vision, not more than hand movements. The family had been celebrating Christmas and the two sons became quarrelsome. In trying to separate them the patient received a heavy blow with a fist in his right eye and the lens was dislocated into the anterior chamber. We dealt with it in the usual way under a general anaesthetic. A needle was passed into the dislocated lens from the limbal area, to fix the lens and given to the house-surgeon to hold, a keratome section was made and the lens extracted with a vectis. He left hospital with perception of light and we did not see much more of him. 